\title{
LENGUA, NORMA Y MEDIOS DE COMUNICACIÓN
}

\author{
Alberto Barahona Novoa
}

\begin{abstract}
RESUMEN
En este artículo se examinan las relaciones entre lengua, norma y medios de comunicación; de manera que se comprende la manera en que los medios de comunicación promueven una variedad lingüística normalizada y prestigiosa. En el ámbito hispano, con bastante éxito se han desarrollado políticas reguladoras entre los comunicadores sociales a fin de mantener una norma compartida en toda la extensa geografía hispanohablante. Así las cosas, se revisan detalladamente los principales principios presentados como guías. También se reseñan las principales investigaciones en Costa Rica que han analizado las variedades lingüísticas presentes en la radio y la prensa escrita.

Palabras clave: norma, lengua, medios de comunicación, lexicoestadística, dialectología hispánica.
\end{abstract}

\begin{abstract}
This paper examines the connection among language, standard and mass media to better understand how mass media fosters prestigious and standardized linguistics. At the Hispanic level, the development of regulatory policies among social communicators has been quite successful to maintain a common standard throughout the vast Spanish-speaking geography. The main principles, presented as guidelines, are examined in detail. The most important research undertaken in Costa Rica on linguistic variability in written press and radio is also examined.

Key words: standard, language, mass media, lexicon-statistics, Hispanic dialectology.
\end{abstract}

\section{Lengua y norma}

Los hablantes, cuando usan un sistema lingüístico, están conscientes del valor de las palabras como elementos portadores de sus ideas. La palabra es la moneda de intercambio. Intuitivamente, los emisores las consideran como las unidades mínimas del sistema, aunque los estudios lingüísticos han demostrado la existencia de morfemas o monemas ${ }^{1}$, según sea la

M. L. Alberto Barahona Novoa. Profesor asociado de la Escuela de Filología, Lingüística y Literatura de la Universidad de Costa Rica.

Correo electrónico: abanovoa@yahoo.com

Recepción: 12- 12- 2008

Aceptación: 30- 01- 2009 
escuela. De ello, se desprende que el estudio del léxico sea pieza fundamental para comprender la relación de los hablantes y el sistema. Estas investigaciones son los pilares para el establecimiento de las relaciones entre los conglomerados sociales y los sistemas lingüísticos.

En sociolingüística, se ha esbozado el concepto de norma, fundamento para entender la teoría del lenguaje humano y sus variedades. Esta construcción teórica se ha convertido en la mejor herramienta linguiística para comprender la actividad comunicativa de los hombres. Con ella, la explicación de la existencia de diversas formas lingüísticas dentro de una comunidad surge directamente de sus procesos sociales integradores y configuradores; de esta manera, se desechan las aproximaciones de filiación subjetiva o de valoración ideológica.

La configuración de ese concepto se remonta a los inicios de la lingüística moderna con el ginebrino Ferdinand de Saussure, quien postuló la distinción entre lengua (langue) y habla (parole). La lengua sería una especie de plural del habla colectiva, el concepto común que se extrae de los lenguajes individuales; por su parte, el habla constituiría el funcionamiento lingüístico momentáneo del individuo. Esta descripción, tal vez, peque de escueta; pero encierra el punto medular de la propuesta de Saussure o, por lo menos, la interpretación que tradicionalmente se le ha asignado.

Otros autores retomaron este concepto para sistematizarlo y adecuarlo a sus investigaciones; entre ellos figuran Harold Palmer, Charles Bally, Vigo Brøndal, Trubetzkoy, Porzig y Gardiner. Esta idea caló hondo en los estudios lingüísticos antes del decenio del año cincuenta. Eugenio Coseriu sintetiza sus postulados de la siguiente manera:

\footnotetext{
La lengua, por otro lado, es la condición que hace posible el hablar, es el 'producto' del hablar como tal, o el mismo 'producto' considerado sistemáticamente: es para algunos el acervo lingüístico individual y para otros el llamado acervo lingüístico social, es el sistema abstracto que gobierna el hablar, o es lo espiritual del lenguaje opuesto a lo material, lo virtual opuesto a lo concreto; es suma, o cualquier suma, de actos lingüísticos [...] (Coseriu, 1982: 40).
}

Sin embargo, Warthurg, Pagliaro y el mismo Coseriu iniciaron una revisión exhaustiva de este principio que, a su juicio, apenas había sido esbozado en la doctrina saussureana. Asimismo, señalaron las insuficiencias teóricas del supuesto dualismo entre lengua y habla. Fue, entonces, cuando encontraron en las mismas enseñanzas de Saussure los elementos necesarios para definir una nueva propuesta sobre el lenguaje. A propósito de este punto, señala E. Coseriu:

Por otra parte, colocándonos en el campo del fenómeno lingüístico considerado independientemente del
sujeto (producto lingüístico + forma lingüística), descubriremos que hay elementos que no son únicos
u ocasionales, sino sociales, es decir, normales y repetidos en el hablar de una comunidad, y que, sin
embargo, no pertenecen al sistema funcional de las formas lingüísticas, o sea que ya sobre la base del
llamado 'producto lingüístico' puede establecerse un sistema normal, distinto del sistema funcional que
se establece en el plano superior de abstracción, el de las 'formas lingüísticas' (Coseriu 1981: 55-56).

Asimismo,

En otro lugar, Saussure indica que una idea de 'lengua' puede darse, de manera bastante fiel, mediante una gramática y un diccionario; y aquí, evidentemente, ya no se trata de la lengua entendida como 'sistema lingüístico', sino de un concepto más amplio, dado que la gramática y el diccionario no contienen solo las oposiciones sistemáticas de una lengua, sino todo lo que es normal en las expresiones de una comunidad (Coseriu 1981: 58).

En las anteriores citas se menciona por primera vez la idea de norma, que después será utilizada por E. Coseriu, en 1951, para establecer su propuesta tripartita de la teoría del 
lenguaje. El investigador rumano propone establecer tres categorías: el sistema, la norma y el habla. Tal sistematización está expuesta en el artículo "Sistema, norma y habla", reeditado en el libro Teoría del lenguaje y lingüística general (1982).

La norma no debe entenderse como una política impuesta por una institución, según criterios de corrección y valoración subjetiva de lo expresado, aunque participen en cierta medida en su establecimiento. Es una realidad comprobada de manera objetiva en una lengua, es el conjunto de usos que seguimos necesariamente por ser miembros de una comunidad lingüística. Los seres humanos como sujetos sociales necesitan de la adscripción a comunidades o estratos sociales que le permitan constituir redes de convivencia. Con estos usos lingüísticos tradicionales -que no son entendidos como correctos en primera instancia-, se constituye la norma; en un plano de mayor abstracción, de estos mismos usos se desprende una serie de elementos esenciales e indispensables, de oposiciones funcionales, que constituyen el sistema de una lengua.

Coseriu afirma que sobre la base del mismo hablar concreto, única realidad investigable del lenguaje, han de elaborarse los conceptos de norma y sistema. La norma contiene solo lo que en el hablar concreto es repetición de modelos anteriores; por su parte, el sistema incluye lo que en la norma es forma indispensable, oposición funcional. Al pasar de norma al sistema, se elimina todo lo que es variante facultativa, normal, o variante combinatoria, conservándose sólo lo funcionalmente importante.

Francisco José Zamora, profesor de la Universidad de Valladolid, esbozó el desarrollo que ha sufrido el concepto de norma. En 1985, publicó el artículo "Sobre el concepto de norma lingüística" en el Anuario de Lingüística Hispánica. Su intención es aclarar la enorme ambigüedad que comporta ese concepto y su utilización. Para ello, recorre las teorías de diversos autores, como K. Gloy, W. Hartung, L. I. Skvorcov, A. Jedlicka, O. Axmanova, R. Bartsch y E. Coseriu, entre otros. El fin último de Zamora es tratar de recoger los puntos de vista y proponer "un tratamiento matizado del concepto de 'norma lingüística' que sea especialmente útil para los estudios sociolingüísticos de estandarización de lenguas" (Zamora Salamanca 1985: 228).

Se deduce que el concepto de norma está ligado a los procesos de estandarización de las variedades lingüísticas (Hudson 1981). Por ello, conocer las normas de una comunidad es importante para establecer cuál ha de tomarse como la estándar que, por supuesto, será la que se pueda promover entre los hablantes por medio de la planificación lingüística y la enseñanza de lenguas nacionales.

Conviene, en este punto, presentar los procesos sociales que configuran la norma estandarizada. El mismo profesor Hudson los concibe así:

\footnotetext{
1) Selección. De una forma u otra debe haber sido seleccionada una variedad particular como la que va a ser desarrollada como lengua estándar. Puede que sea una variedad ya existente, como la usada en un centro político o comercial importante, pero también podría ser una amalgama de distintas variedades. [...]

2) Codificación. Alguna institución tal como la Academia tiene que haber escrito diccionarios y libros de gramática para 'fijar' una variedad, de forma que todos puedan ponerse de acuerdo en lo que es correcto. [...]

3) Elaboración funcional. Tiene que ser posible utilizar la variedad seleccionada en todas las funciones asociadas con el gobierno central y con la escritura, por ejemplo en el parlamento y en los tribunales, en documentos burocráticos educativos y científicos de toda clase, y, naturalmente en los diversos géneros literarios. [...]

4) Aceptación. La variedad elegida tiene que ser aceptada por la población afectada como la variedad de la comunidad; de hecho, normalmente como la lengua nacional. [...] (Hudson 1981: 43).
} 
E. Coseriu (1982) expone ejemplos de distintos niveles de la lengua para ilustrar cómo opera la diferencia entre norma y sistema. Parte de hechos de habla de emisores hispanohablantes. Ofrece una amplia serie de ejemplos en el campo de la morfología. Por ello, una de las vías para conocer la norma de una comunidad se encuentra en el estudio del léxico. En este sentido, en este artículo se reseñarán las principales investigaciones realizadas en nuestro país sobre el léxico en los medios de comunicación social. Por medio de análisis estadísticos de las palabras más frecuentes en la radio y la prensa costarricense, se puede alcanzar un conocimiento preciso del inventario léxico de la norma construida por los hablantes nacionales del español. Además, para K. Gloy, un criterio de legitimación de una norma es el predominio en el uso, obtenido del estudio de la frecuencia de aparición de los elementos lingüísticos que conforman una variedad.

Cualquier aproximación al estudio del lenguaje en los medios de comunicación, debe partir del concepto de norma como hecho socio-cultural. El dilema de muchos investigadores es perfilar esa norma. El primer paso, naturalmente, ha de ser identificar los rubros léxicos que conforman esa norma: por ello, las obras mencionadas en el párrafo anterior ayudarán a conocerla por medio de la variedad promovida en los medios de comunicación social.

Sirecordamos que Hudson menciona la codificación como un proceso de estandarización de las lenguas, fácilmente comprenderemos que los diccionarios -como inventarios léxicosactúan como catalizadores en la conformación de las normas. En la Universidad de Ausburgo, un grupo de lingüistas se ha dedicado al estudio y práctica de la lexicografía. Esta tarea los ha conducido a la investigación de las relaciones entre la norma, los diccionarios y el léxico. En el artículo "La variación lingüística en lexicografía", Stefan Ettinger distingue tres apartados, a saber: el diccionario y el sistema lingüístico, el diccionario y la norma y, por último, el diccionario y el habla. Este autor menciona la existencia de tres tipos de norma: tipológica, estadística y prescriptiva. En este sentido, es valioso repasar sus consideraciones sobre la norma estadística, en la cual se acepta todo aquello que se produce en una lengua como uso lingüístico normal. Para Ettinger, esta norma puede registrarse por medios estadísticos.

\begin{abstract}
Hoy se entiende por norma estadística aquella norma de una lengua que, por comprobación numérica, es la más extendida y aceptada en general por los hablantes. De este modo, la norma estadística representa un corte transversal sincrónico de una lengua viva que reúne en sí influencias históricas y normas prescriptivas aceptadas. La norma estadística se distingue de la prescriptiva en que esta última exige muchos hechos lingüísticos que no siempre son realizados de hecho por los hablantes. Desde un punto de vista histórico, la norma estadística precede en las lenguas naturales a la norma prescriptiva, ya que, si bien una norma prescriptiva puede intentar frenar, orientar o desviar evoluciones lingüísticas, no puede crear reglas totalmente contrarias al sistema, es decir, contrarias a la lengua. Por lo tanto, las buenas normas prescriptivas deben seguir el uso lingüístico real y, en caso de duda, deberían adoptar la forma más usual (Haensch 1982: 361-362).
\end{abstract}

La norma estadística representa bastante objetivamente el vocabulario. Se entiende como la norma de comprobación numérica, la que más se extiende y es aceptada en general por los hablantes. Representa un corte transversal sincrónico de una lengua viva que reúne, en sí, influencias históricas y normas prescriptivas aceptadas. Cuenta con la ventaja de que se registran solo los actos realizados por los hablantes y, por lo tanto, conformes al sistema.

Por esas ventajas, muchos diccionarios actuales se basan en estudios estadísticos. En el ámbito hispanoamericano, este criterio fue utilizado para redactar el Diccionario del español de México, propuesta de Luis Fernando Lara y sus colaboradores. Pese a las bondades de este método, Ettinger encuentra algunos inconvenientes en el establecimiento de 
la norma estadística. Enumera los siguientes: a) se parte fácilmente de la idea de que se puede obtener un promedio matemático del uso de todos los hablantes de una lengua determinada, se supone que partiendo de un número infinito de hablantes se puede establecer un valor medio calculado; b) se plantea la obtención del corpus sin tener definido con claridad cuál es el objeto de investigación; las lenguas naturales son realidades de estudio bastante complejas, sometidas a variantes diacrónicas, diatópicas, diafásicas, diastráticas y diaintegrativas; c) las descripciones del uso lingüístico real de una comunidad de hablantes tienden a convertirse en norma prescriptiva (Ver Haensch 1982: 363-ss).

No obstante estas limitaciones, Ettinger considera la norma estadística un avance importante para el conocimiento del léxico. La reconoce como la mejor herramienta actual para conocer la lengua común y su norma de prestigio. En su criterio, tal vez haya que mejorar teórica y prácticamente los procedimientos; pero los resultados pueden ser reveladores.

En las investigaciones sobre el léxico de los medios de comunicación costarricenses, el criterio estadístico ha sido aplicado a un corpus delimitado de por sí: se trata de recopilaciones de usos normales difundidos por la radio y la prensa en el territorio nacional. Es decir, la estadística solo recoge una muestra representativa de los modelos lingüísticos que se les ofrecen a los oyentes y lectores. Por otra parte, estos estudios no han aspirado a ser exhaustivos en cuanto a la determinación de la norma lingüística costarricense. Es obvio que deben estudiarse otras variedades de lengua (estilos, jergas, registros y tecnolectos), para alcanzar una descripción completa de los usos lingüísticos costarricenses.

Raúl Ávila, en su visita a Costa Rica en marzo de 1996, comentó la importancia de conocer y determinar las normas cultas estandarizadas en Hispanoamérica, para las industrias de comunicaciones. La publicación de manuales patrocinados por las grandes empresas periodísticas demuestra que, por lo menos en el mundo hispánico, existe la ambición de alcanzar la estandarización de la variedad culta a fin de asegurar el entendimiento entre todos los hablantes actuales del español. Incluso, los recursos cibernéticos actuales posibilitan la consulta inmediata de obras como consultores idiomáticos, vademécum y bases de datos. La agencia EFE patrocina la muy conocida Fundación del Español Urgente (Fundéu) ${ }^{2}$, donde los comunicadores sociales pueden consultar los usos privilegiados por las normas de prestigio del mundo hispanohablante.

Ya se ha mencionado que toda norma estadística -obtenida del uso-deviene tarde o temprano en norma preceptiva; muchas veces así convertida por los mismos hablantes, ante el temor de recibir una sanción social como desconocedores de los usos considerados "cultos", que les impedirían ascender en el escalafón social.

S. Ettinger expone, finalmente, varias condiciones que posibilitan imponerla. Así exterioriza la siguiente realidad:

Una norma prescriptiva será tan buena como lo sean las posibilidades de imponerla. Aquí se pueden distinguir dos grandes ámbitos:

1) Los 'multiplicadores' en la sociedad (es decir, en general, los grupos profesionales con gran prestigio social, como, por ejemplo, profesores universitarios, juristas, periodistas, etc.), los medios de comunicación social (prensa, radio y televisión) y las instituciones públicas, sobre todo la enseñanza [...]

2) El segundo grupo lo constituyen las obras lingüísticas de índole normativa, es decir, principalmente las gramáticas, los diccionarios y otras obras de consulta, así como las revistas cuyo objetivo es la defensa de la pureza de la lengua (Haensch 1981: 376-377).

Esta última cita nos introduce en el siguiente apartado, donde se examinarán la vinculación entre la norma, la identidad cultural y los medios de comunicación masiva. 


\section{Lengua y medios de comunicación}

En la opinión popular, establecer una relación entre el habla difundida por los medios electrónicos y las costumbres linguiísticas de una comunidad es un lugar común. Las críticas básicamente se han dirigido a la acción de la televisión ${ }^{3}$; sin embargo a la radio también se le podrían endilgar las mismas valoraciones, incluso con más ahínco, pues es sabido que el alcance de este último medio es mayor. La facilidad para adquirir un equipo de radio y la difusión de sus ondas le permiten cubrir mayores extensiones territoriales y, por lo tanto, estar a la disposición de una gran cantidad de personas. Las posibles influencias perniciosas de la radio no solo afectan las costumbres lingüísticas, sino también se ha citado ámbitos de otro orden como la salud, el poder de crítica y la capacidad de aprendizaje.

Por este motivo, existe una corriente de autores que abogan por el buen uso de la lengua, es decir la utilización de una variedad lingüística sancionada positivamente por instituciones legitimadoras. Los medios de comunicación han de ser canales de propalación de las normas cultas de una región, configurándose como verdades métodos propedéuticos de acción formadora. Al respecto Vicente Romano arguye que todo análisis de la lengua en los medios de comunicación debe desembocar en la correcta formación de los comunicadores:

\footnotetext{
El buen estilo y lenguaje correcto aprovechan al lector, al oyente y al espectador. Hasta ahora, los estudios sobre el lenguaje y estilo del periodismo se han limitado a establecer características de determinados géneros, de rasgos individuales, etc. Pero se sabe ya que lo que influye en los receptores no es la noticia o aportación aislada, individual, sino el conjunto de la comunicación social en su continuidad temporal y en su paralelismo medial. De ahí que el esfuerzo por mostrar y comprender los problemas del lenguaje y estilo empleados en los medios de comunicación pueda aportar también sugerencias a la formación de los comunicadores profesionales. Pues, cuando se muestra la realidad tal cual es, se indica al mismo tiempo lo que hay que modificar en ella (Fontanillo 1990: 9).
}

Raúl Ávila se ha ocupado de analizar este fenómeno. Luego de un arduo escrutinio de las publicaciones al respecto, concluye que:

\footnotetext{
Sucede, sin embargo, que los comentarios en torno al lenguaje de la televisión -hasta donde he podido obtener información- no pasan de ser opiniones con mayor o menor fundamento, o en el mejor de los casos, investigaciones sin una base empírica y estadística suficiente (Ávila 1991: 1).
}

También, los profesores universitarios, filólogos y miembros de academias consideran que los medios de comunicación propalan vulgarismos, idiotismos, barbarismos y "anormalidades" de la lengua. Así lo expresaron en la Universidad de Salamanca, con motivo de la conmemoración del décimo aniversario del noticiario mexicano 24 horas.

En otras regiones de Hispanoamérica, se ha debatido mucho acerca del tema. En 1982 y desde el seno de la Comisión para la Defensa de la Lengua Española, E. de la Peña apela a los amantes de la lengua para que escapen los giros vitandos, las vulgaridades y los elementos contaminantes que confluyen en la televisión. Además, advierte que:

El peligro que corre, no sólo nuestra lengua en bocas que no tienen interés alguno en conocerla mejor, sino el público que recibe, casi como una comunión, los mensajes que se le quieren transmitir. A mayor influencia de personas mal preparadas, corruptoras del lenguaje, mayor riesgo de infección en el habla de los telespectadores (Peña 1982: 21).

En España se han emitido criterios muy semejantes a los expuestos. En este caso, J. A. Fernández (1988) los expone en su artículo "La fonología en la televisión española: violencias fonéticas”. Según este autor, en el español de los medios de comunicación de masas, 
se encuentran "violencias, anomalías, deformaciones, barbarismos, neologismos, alteraciones, extranjerismos, etc" (Fernández 1988: 249).

Eddie González, en Venezuela, publica "El pobre lenguaje de la televisión” en 1988. Poco después, salió a la luz el libro "Teleperversión de la lengua" que publicaron Enrique Fontanillo y María Isabel Riesco en España. Estas obras carecen de una metodología establecida, incluso Fernández reconoce que el material de estudio fue seleccionado un tanto al azar durante diez años. González afirma que su análisis se basó en la observación directa y casual, sin una metodología establecida. Fontanillo y Riesco no explican la metodología empleada, el lapso utilizado para recoger la muestra, o bien, el porcentaje de aciertos -según la norma- frente al de errores.

En 1990, la revista Lingüística española actual publicó una serie de artículos que insistían en la presencia de corruptelas en el español de los medios de comunicación. No obstante, también exponían otro gran tema en torno a la relación lengua y medios. Manuel Alvar y J. L. Martínez Albertos señalan la importancia de conocer el español de la radio y la televisión, pues lo consideran un elemento importantísimo para guardar la unidad de la lengua, antes aún no lo rechazan de plano. Martínez Albertos se pliega a la idea del Congreso de Academias de Lengua Española (1985) de que, en los noticiarios de televisión y en los radionoticiarios, existan secciones de orientación gramatical. Apoya sus observaciones con una cita del "Manual de estilo de la Agencia EFE", que reza:

\footnotetext{
La unidad de la lengua es un bien que importa defender en el seno de la comunidad hispanohablante. Hoy la prensa, la radio y la televisión ejercen una influencia idiomática superior a la del sistema docente. Sin exageración puede afirmarse que el destino que aguarda al español -o cualquier otro idioma- está en sus manos (Martínez 1990: 186).
}

El seminario “Diálogo triangular Iberoamérica-España-EE.UU.” (1991), organizado por el Colegio de México, dedicó una sesión al tópico de la lengua española ante la globalización de los medios. En síntesis, las ideas ahí discutidas versaban sobre la responsabilidad de los medios en el manejo de la lengua española y su mal empleo, la importancia de la televisión para mantener al español en países como Estados Unidos, la aceptación de las grandes isoglosas del español y la cooperación poligonal de todos los países hispanoamericanos, sin la necesidad de contender con la norma castellana.

No solo los círculos académicos han discurrido sobre el tema. En periódicos, empresas radiofónicas y agencias internacionales de prensa, se ha gestado un movimiento de defensa participativa de la lengua; pero más interesante es la preocupación por mantener el entendimiento en medio de la polifonía dialectal hispánica. Por su carácter normalizador, el "Manual de español urgente" de la Agencia EFE y el "Libro del estilo de ABC" gozan de gran acogida entre los comunicadores. Medios como El País, Radio Nacional de España (RNE), Televisión Española (TVE), OTR Press disponen también de libros de estilo. Incluso en nuestro país, periódicos como La Nación cuentan con sus manuales de estilo o reglas de redacción. Este panorama demuestra cómo la lengua de los medios se ha convertido en una gran veta de investigación.

En octubre de 1989, la Agencia EFE y la Fundación Germán Sánchez Ruipérez organizaron el I Seminario Internacional "El idioma español en las agencias de prensa", con el afán de aunar criterios y de sentar las bases de una futura colaboración para una mejor defensa del español. En esa cita internacional, Raimundo Riva Palacio de NOTIMEX (México) afirmó que los medios de comunicación han contribuido a crear un idioma más universal, y han enriquecido nuestros dialectos con palabras y expresiones que antes eran solo 
localismos y ahora son acervo del mundo hispánico. Es decir, según su criterio, se encara una homogenización del diasistema español, ante una nueva concepción de las normas generales, sin ir más allá, ante una norma supranacional en consonancia con la globalización de las relaciones planetarias. La lingüística hispánica debe atender este fenómeno, es necesario estudiar esta nueva entidad lingüística que nos liga y permite la comunicación, sin muchos problemas, desde los Pirineos hasta la Tierra del Fuego.

En el antes citado Seminario, los participantes emitieron una serie de recomendaciones que hoy se conocen como la "Declaración de Madrid". Esta lista de principios devela la importancia de ofrecer investigaciones sobre el español, desde una perspectiva teórica bien definida ${ }^{4}$.

Otras voces se alzan para solicitar nuevos acercamientos a este problema. Las mismas Academias de la Lengua se perfilaron como las nuevas abanderadas de esta cruzada. El Congreso de 1985 presentó diecisiete propuestas en defensa del castellano. La primera, octava y novena conciernen a la relación entre la lingüística y los medios de comunicación; así lo plantearon:

\footnotetext{
1.-Resulta particularmente importante el análisis de la lengua en los periódicos y revistas, porque se trata de un registro que goza de mayor permanencia que los que corresponden a otros medios de comunicación. $[\ldots]$

8.-Hay que fomentar en los diarios, radionoticieros y noticieros de televisión columnas o secciones de orientación gramatical.

9.-Antes de señalar errores o vicios es necesario que los lingüistas analicen y describan el estado de la lengua en la prensa (citado por Martínez 1990: 176)
}

Haciendo eco de estas propuestas, la Fundación Centro de Educación a Distancia para el Desarrollo Económico y Tecnológico, conocida por su acrónimo Ceddet, organización española dedicada a la educación a distancia, imparte desde el año 2006 un curso dirigido a comunicadores hispanohablantes, a fin de adiestrarlos en el uso de una norma culta estandarizada para todos los países de la comunidad iberoamericana. Este curso se nomina "El uso correcto del español en los medios de comunicación”, cuya orientación prescriptiva se evidencia desde su mismo título. Este esfuerzo repite la idea de difundir un ideal de corrección canónica, aunque no se aclara suficientemente si se ha tomado en cuenta el mosaico dialectal del español actual. En la siguiente cita, se trasluce esta intención:

\footnotetext{
En una reunión como esta, dedicada al lenguaje y la comunicación, hay que recalcar la responsabilidad de los periodistas en la defensa del buen uso de la lengua. Es ya casi un lugar común afirmar que los periodistas utilizan mal el español; no es cierto, la verdad es que la mayoría lo utilizan bien o incluso muy bien; pero basta con que unos pocos lo descuiden para que sus errores y sus desvíos de la norma lleguen a muchísimas personas.

Este es el poder de la prensa: lo que escribe un periodista llega a cientos de miles, a millones de personas, muchas de las cuales tienden a tomar como modelo el lenguaje de la prensa, y si ese modelo no es bueno, si esconde errores o malos usos, los resultados pueden ser negativos.

Y esa responsabilidad ya se extiende a la Internet, pues cada vez son más los periódicos y las revistas en español que tienen edición electrónica, edición on line, para usar el término inglés específico, y pueden leerse en cualquier parte del mundo en la pantalla de una simple computadora, el ABC de Madrid, el Clarín de Buenos Aires, El tiempo de Bogotá o El Nacional de Caracas, entre otros (Ceddet 2005: 24, módulo 3).
}

En este mismo orden de preocupaciones, Martínez Albertos define un tipo de lengua que conviene a los medios de comunicación masiva, según su criterio:

\footnotetext{
El lenguaje periodístico debe utilizar una lengua fijada, normalizada, estándar, una lengua donde exista ya un elenco preciso de modos de narrar, de describir, de comentar. Esta lengua permite también una fácil lectura y descodificación, con las mayores garantías de adecuado respeto al contenido que se quiso emitir (Martínez Albertos 1990: 181).
} 
Para satisfacer este ideal, los académicos de la lengua ya propusieron el único medio para alcanzarlo: se deben fomentar los análisis objetivos del sistema lingüístico difundido por los medios de comunicación.

A manera de respuesta, el proyecto dirigido por el Dr. Raúl Ávila del Colegio de México, "Difusión Internacional del Español por radio y televisión: unidad y diversidad de la lengua (DIES-RTV)" -que recoge y procesa las normas lingüísticas regionales de México, Argentina, Cuba, Radio Vaticana, Chile, Venezuela, Canarias, Andalucía, España (nacional), Colombia y Uruguay-, trata de responder a preguntas tales como

\begin{abstract}
¿Es pobre el lenguaje de la radio y la televisión? ¿En qué medida los medios electrónicos de difusión masiva contribuyen a la unidad de la lengua y a la comunicación nacional e internacional? ¿Qué diferencia existe entre el habla prestigiosa de una región o de un país y el lenguaje de esos medios? ¿Cómo se puede fomentar la unidad de la lengua sin menoscabo de la diversidad que la enriquece? (Ávila 1991: 7).
\end{abstract}

Esta aproximación destaca por sus acertados cuestionamientos de cómo se ha tratado la relación de lengua y medios de comunicación. En primer lugar, cuestiona la difundida idea de la pobreza de los lenguajes de radio y televisión. Es decir, los investigadores tienen el compromiso de estudiar las variedades difundidas en su real condición, antes de pretender ajustarlas a normas de prestigio concebidas muchas veces en los escritorios de académicos o "puristas" de la lengua. Simultáneamente, es necesario el análisis de los factores sociolingüísticos de los medios de comunicación. Surgen inquietudes como la verdadera importancia de los medios frente a otros sistemas de programación lingüística, como el sistema escolar de cada país hispanohablante. Por otra parte, el español es lengua oficial de más de veinte naciones, por lo que los estudios deben tomar en cuenta esa poliforme realidad dialectal. Razones como esta justifican que los esfuerzos deben ser conjuntos para entender en la justa medida la configuración de normas supranacionales favorecidas por los procesos de integración que promueve la nueva globalización mediática. Por último, esta propuesta de estudio es respetuosa de la variedad cultural e idiosincrasias lingüísticas. No se puede proceder a imposiciones inquisitoriales en favor de una pretendida unidad lingüística en todo el ámbito hispanohablante. Se debe partir de las nociones de lealtad lingüística, así como de la irrefrenable evolución y enriquecimiento del español como diasistema lingüístico.

\title{
3. El lenguaje de la radio
}

Manuel Alvar (1990) se pregunta si se ha constituido un lenguaje específico de los medios de comunicación. Las experiencias en algunos países han sido definitivas para suponer que el lenguaje de los medios está manipulado para que transmitan comunicaciones "interesadas", es decir, políticas. Así lo demuestra la existencia de la llamada, "industria del habla", donde se siguen estrictos criterios para el doblaje de producciones de televisión y cinematográficas, con el objeto de alcanzar una variedad políticamente correcta.

En Inglaterra, la British Broadcasting Corporation (BBC) decidió favorecer, en 1926, el sociolecto de las clases altas; en el fondo, existía un interés elitista. No obstante, sus directores nunca olvidaron que la lengua debía ser uniformada para que cumpliera con su finalidad. Se plantearon así los cuatro pilares que debía presentar la lengua de la radio: selección de una variedad, su codificación, el alcance de su uso en los diversos programas y la relación del uso de esa lengua con la realidad. Se creó un sistema nunca hablado, pero válido y correcto para transmitir ciertos programas. La base de este lenguaje era el dialecto de Oxford y Cambridge, al cual se le llamó "recieved pronunciation" (RP). 
Luego de la Segunda Guerra Mundial, esta lengua volvió a sufrir ciertos cambios. La BBC, desde 1979, ha ido creando un lenguaje estándar basado en criterios bastante tradicionales: repudio de los errores fonéticos o gramaticales y aceptación de las actitudes lingüísticas de la generación media. En este ejemplo, se visualiza que la lengua de la radio tiene un alto valor para la estratificación social de la población. En otros países, como Turquía, esa lengua se utilizó para fines políticos integradores y centralistas. En síntesis, la lengua de la radio es un instrumento de socialización que ha de ser conocida para determinar cuál será la planificación lingüística por aplicar.

Ante la pregunta, ¿cuál variedad ha de ser promovida por los medios de comunicación?, Alvar responde que "la lengua aceptada por todos y no repudiada por nadie, con lo que las lenguas de grupo o los dialectos deberán reservarse tan sólo para los programas que se dediquen a las audiencias limitadas por los intereses que expresan tales modalidades" (Alvar 1990: 158). En esta opinión está implícita la clave de cualquier estudio: debe conocerse la norma estándar para luego difundirla y programar las estrategias para la planificación lingüística.

Raúl Ávila, durante una conferencia dictada en la Universidad de Costa Rica en marzo de 1996, opinó que, en algunos países, la radio y la televisión han respondido a las inquietudes de Manuel Alvar. En Italia se logró la unificación política antes que la linguiística. En este sentido, el teatro en el siglo pasado, la radio en el decenio del cuarenta y la televisión en los años cincuenta, unificaron el italiano, pues son medios que rebasan la barrera del analfabetismo. La radio goza de una ventaja sobre los otros medios, por cuanto su producción es muy barata frente a los costos que supone un programa televisivo o la edición de periódicos. De esta manera, se alcanzó una estandarización de la lengua italiana, cuya base fue el dialecto toscano. El profesor Etsain del Colegio de México señala que una situación muy parecida ocurre con la difusión del árabe. Existe una norma internacional -árabe moderno literario- que permite la comunicación desde Irak hasta Argelia; este lenguaje es precisamente el utilizado por la televisión y la radio. En países de reciente descolonización, como Zaire, la República Centroafricana, India o Singapur, las lenguas de las metrópolis se han constituido en la variedad estándar difundida por los medios de comunicación, y considerada la mejor para lograr la unidad lingüística. Por último, la misma situación se produce en China para solucionar los problemas de comunicación entre la población que habla cantonés y la que utiliza el mandarín.

\section{Estudios en Costa Rica}

En nuestro país, se han presentado los resultados de dos investigaciones sobre el léxico utilizado en la radio y la prensa escrita, siguiendo los postulados de la lexicoestadística. La primera de ellas fue desarrollada por mí como proyecto de graduación para optar al grado de Magíster Linguisticae, en la Universidad de Costa Rica. La segunda versa sobre el léxico de la prensa escrita y estuvo a cargo de Antonio Leoni de León, quien la sometió a consideración de la Escuela de Filología, Lingüística y Literatura, como requisito para optar al grado de licenciado en Filología Española.

El análisis del léxico básico de la radio costarricense arrojó los siguientes resultados:

1. Se estableció un corpus de 2628 unidades léxicas con una frecuencia de aparición significativa de acuerdo con los parámetros establecidos por los investigadores del proyecto 
de Difusión Internacional del español por radio y televisión: unidad y diversidad de la lengua (DIES-RTV), coordinado por el Colegio de México.

2. Este inventario léxico se caracteriza por su alto grado de pertenencia a la norma estándar del español internacional. Llama poderosamente que no aparecieron formas propias de la variedad española costarricense o costarriqueñismos.

3. Los tecnicismos alcanzan un porcentaje de aparición casi despreciable. Las condiciones de la comunicación radiofónica exigen el tratamiento de temas y variedades lingüísticas generales, que no impliquen un alto de grado de especialización de los oyentes.

En cuanto a la investigación sobre el léxico básico de la prensa escrita costarricense, se obtuvieron las siguientes conclusiones:

1. Se configuró un corpus de 8303 vocablos que son considerados el léxico básico de la prensa escrita costarricense.

2. Al igual que el léxico de la radio costarricense, existe un alto grado de estandarización y una ínfima presencia de voces dialectales costarricenses.

Estas investigaciones son los primeros intentos de fijación de la norma costarricense difundida en los medios de comunicación.

\section{Conclusiones}

En la dinámica de la comunicación social, la existencia de normas estándares es un fenómeno decisivo; pues son ellas las encargadas de permitir el convenio social entre los individuos. Ahora bien, el establecimiento de una norma estándar ha de partir de un proceso de investigación que permita la dinamización de los procesos sociales en su justa medida.

Hasta hace muy poco, los estudios filológicos y de comunicación habían puesto el énfasis en la adopción de normas prescriptivas, emanadas de los centros controladores del poder. En el caso de Hispanoamérica, el escenario era más desalentador, ya que las normas nacionales se determinaban siguiendo los usos y costumbres, sancionados positivamente por la Real Academia Española. Así se privilegiaba la variedad peninsular como modelo de corrección para todas las regiones donde se hablara español.

Sobre los medios de comunicación, se ejerció una fuerza coercitiva para que difundieran únicamente aquellas formas que se ajustaran a esa norma ideal, correcta y pura; aunque extraña y ajena a las realidades de las comunidades a las que se les ofrecía comunicación.

El desafío para los comunicadores, en asocio con lingüísticas y pedagogos, consiste en el establecimiento de una norma fundada en los usos reales de los conglomerados sociales. Una norma lingüística que surja de las actualizaciones del lenguaje, como sistema diaintegrativo de las aportaciones de todos los niveles, registros y estilos del español costarricense.

El derrotero ya está prefigurado, en el caso de los medios costarricenses. Urgen más investigaciones como las comentadas en el anterior apartado de este artículo; a fin de obtener un cabal conocimiento de la norma que ha de servir para la transmisión de la realidad nacional. Un tipo de norma, configurada de esta manera, necesariamente coadyuvará a la ansiada democratización de la información, pues se plasmará en formas lingüísticas conocidas y aceptadas por toda la ciudadanía costarricense. 


\section{Notas}

1. Morfema (neol. A partir de morfo(logía) y -ema*) J. Baucdouin de Courtenay en 1881 introduce el término (fr. y pol. Morfema) para designar la mínima unidad dotada de significado para luego distinguir, según el valor léxico o gramatical, mm. semasiológicos y mm. Morfológicos; el término es más tarde adoptado en francés por Vendryes y Meillet (morphéme) para indicar solo los morfemas morfológicos ( $\rightarrow$ formante), mientras que los mm. Semasiológicos son llamados más bien semantemas*. Para el Círculo de Praga el m. es una unidad morfológica no susceptible de una ulterior descomposición en unidades menores; para Bloomfield y la escuela americana (ingl. morpheme) un morfema es cada una de las unidades significativas, para Martinet (1996:20), en cambio, el m. es un monema pertinente a la gramática (Cardona 1991: 187-188).

monema (neol. De mono-* y -ema*) Término de H. Trei para indicar la unidad mínima analizable en una sucesión de otras unidades del mismo tipo, un signo cuyo significado 'no sea divisible en significantes más pequeños’ (1950: 162, cfr. también 1941:51, 1948:69). El término ha sido retomado por Martinet, que lo define como cada una de las modificaciones del enunciado que correspondan a una modificación del sentido, para indicar las unidades que resultan de la primera articulación (Cardona 1991: 186).

2. Su dirección electrónica es www.fundeu.es

3. Sobretodo si se tiene en cuenta el poder de los periodistas, en especial el de los que aparecen en la pantalla, para suscitar en los consumidores de comunicación pautas de comportamiento tendentes a la imitación de quienes consideran más importantes y expertos que ellos. Esta circunstancia, verificada por los estudios de comunicología, induce igualmente a pensar que el buen uso del lenguaje contribuiría a perfeccionar el de los telespectadores (Fontanillo 1990: 8).

4. Se establecieron cinco principios: 1. Proponer a las respectivas direcciones la convocatoria de una reunión anual de los responsables de los servicios en lengua española de las distintas agencias informativas, para debatir y armonizar las cuestiones relativas al uso del idioma en el ejercicio periodístico. 2. Favorecer el intercambio de redactores, mediante el desarrollo de programas cuya adopción, se recomendarán a los medios que representen. 3. Dar los pasos necesarios para comenzar la redacción de un manual sobre el uso periodístico del español, destinado a los servicios en este idioma de las agencias de prensa. 4. Recomendar a la Agencia EFE que enriquezca las sucesivas ediciones de su Manual de Español Urgente con las aportaciones de los seminaristas. 5. Establecer un sistema de intercambio y consulta permanente entre las agencias participantes en torno a cuestiones lingüísticas y recomendar la preparación de un índice temático de bibliografía sobre agencias informativas.

\section{Bibliografía}

ABC. 1993. Libro del estilo. España: Ariel

Alvar, M. 1990. "Medios de comunicación y lingüística”. Lingüística española actual. Vol. 12 (2). Madrid: Instituto de Cultura Iberoamericana, 150-170.

Ávila, R. 1991. Los medios electrónicos de difusión y las normas nacionales e internacionales de la lengua. La Habana: Segundo encuentro de centros de formación permanente, Centro de estudios de la radio y la televisión. Instituto Cubano de Radio y Televisión. 
Barahona, J. 1996. Léxico básico de la radio costarricense. Tesis de Maestría: Universidad de Costa Rica.

Cardona, G. 1991. Diccionario de lingüística. Barcelona: Editorial Ariel, S. A.

Coseriu, E. 1981. 'Los conceptos de ‘dialecto', ‘nivel' y 'estilo de la lengua' y el sentido propio de la dialectología”. Lingüística española actual. 3 (1): 1- 32.

1982. Teoría del lenguaje y lingüística general. Madrid: Gredos.

El País. 1996. Libro de estilo. Madrid: Ediciones El País, S. A.

Fernández, J. A. 1988. "La fonología en la televisión española: violencias fonéticas”. Revista de dialectología y tradiciones populares. Madrid. (43): 240- 276.

Fontanillo, E. y M. Riesco. 1990. Teleperversión de la lengua. Barcelona: Anthropos.

Fundación Centro de Educación a Distancia para el Desarrollo Económico y Tecnológico, (Ceddet). 2005. "El uso correcto del español en los medios de comunicación". Madrid: Módulos del curso homónimo, impartido vía Internet. http://www.ceddet.org. Consulta: Mayo de 2005.

Haensch, G. et al. 1982. La lexicografía. Madrid: Gredos.

Hudson, R. A. 1981. La sociolingüística. Barcelona: Anagrama.

Leoni, J. 1997. Léxico básico de la prensa costarricense. Tesis de Licenciatura: Universidad de Costa Rica.

Martínez Albertos, J. L. 1990. "El uso de la lengua en la comunicación periodística: aspectos culturales, políticos y sociales”. Lingüística española actual, 12. Madrid: Instituto de Cooperación Iberoamericana, 170-190.

Peña, E. de la. 1982. "El lenguaje de la televisión”. La política lingüística de México. 2. México: Comisión para la defensa del idioma español, 15-25.

Zamora Salamanca, F. 1985. "Sobre el concepto de norma lingüística”. Anuario de lingüística hispánica. Madrid: Instituto de Cooperación Iberoamericana. 1 (12): 220- 245. 